\title{
Rescue $N$-butyl-2 cyanoacrylate embolectomy using a Solitaire FR device after venous glue migration during arteriovenous malformation embolization: technical note
}

\author{
Robert Fahed, MD, ${ }^{1}$ Frédéric Clarençon, MD, PhD, ${ }^{1}$ Nader-Antoine Sourour, MD, ${ }^{1}$ \\ Dorian Chauvet, MD, ${ }^{2}$ Lise Le Jean, MD, ${ }^{3}$ Jacques Chiras, MD, PhD, ${ }^{1}$ and Federico Di Maria, MD ${ }^{1}$ \\ Departments of ${ }^{1}$ Interventional Neuroradiology, ${ }^{2}$ Neurosurgery, and ${ }^{3}$ Anesthesiology, Pitié-Salpêtrière Hospital, Paris, France
}

\begin{abstract}
One of the procedural risks in arteriovenous malformation (AVM) embolization is possible migration of the embolic agent into the venous drainage with an incomplete nidus occlusion, which may lead to severe hemorrhagic complications.

This report presents the case of a 29-year-old man who presented with a deep intraparenchymal hematoma on the left side secondary to the spontaneous rupture of a claustral AVM. Upon resorption of the hematoma, the patient underwent an initial therapeutic session of $\mathrm{N}$-butyl-2 cyanoacrylate endovascular embolization, with the purpose of reducing the AVM volume and flow before performing Gamma Knife radiosurgery. After glue injection into one of the arterial feeders, the control angiography showed a partial migration of the glue cast into the straight sinus, with most of the nidus still visible. Because of the bleeding risk due to possible venous hypertension, it was decided to try to retrieve the glue from the vein by using a stent retriever via jugular access. This maneuver allowed a nearly complete removal of the glue cast, thereby restoring normal venous flow drainage. The patient showed no clinical worsening after the procedure.
\end{abstract}

To the authors' knowledge, this is the first report of the use of the Solitaire FR device as a rescue glue retriever. This method should be considered by physicians in cases of unintended glue migration into the venous circulation during AVM embolization.

http://thejns.org/doi/abs/10.3171/2015.5.JNS15145

KEY WORDS arteriovenous malformation; N-butyl-2 cyanoacrylate; Glubran; migration; stent retriever; Solitaire FR; vascular disorders

$\mathrm{B}$ RAIN arteriovenous malformations (bAVMs) are a rare vascular disease. ${ }^{1}$ The most frequent revealing condition of bAVMs is hemorrhage, encountered in about half of symptomatic bAVMs. ${ }^{3}$ Brain AVMs represent $2 \%$ of all cerebral hemorrhage etiologies. ${ }^{13}$ Rupture of bAVMs may lead to severe neurological deficit or fatal outcome, with a mortality rate as high as $29 \% .^{2}$ Although aggressive treatment of unruptured bAVMs has been debated since the early results of the ARUBA (A Randomized Trial of Unruptured Brain Arteriovenous Malformations) study were published, ${ }^{8}$ endovascular treatment allows an immediate occlusion of the nidus and remains a valuable option in cases of ruptured AVMs, which present a high risk of rebleeding. ${ }^{1}$ The procedure aims to obliterate the whole nidus as well as restore normal venous drainage of the AVM. Once the draining veins are occluded, any that remain - even as part of the nidus - are potentially at risk for hemorrhage. In such situations, physicians may be confronted with accidental migration of the embolic agent into the draining veins. We report the case of an accidental $N$-butyl-2 cyanoacrylate (NBCA) migration into the straight sinus through the draining vein during AVM embolization, which was treated by mechanical retrieval using a Solitaire stent (ev3/Covidien) via a venous approach.

\section{Illustrative Case}

A 29-year-old, right-handed man presented with acute right hemiparesis. Unenhanced brain CT revealed a 4-cmdeep hematoma on the left side (Fig. 1A). Digital subtraction angiography (DSA) was performed and showed a bAVM of the claustrum, fed mainly by left lenticulostriate

ABBREVIATIONS AVM = arteriovenous malformation; $b A V M=$ brain AVM; DSA = digital subtraction angiography; $N B C A=N$-butyl -2 cyanoacrylate . SUBMITTED January 22, 2015. ACCEPTED May 7, 2015.

INCLUDE WHEN CITING Published online November 27, 2015; DOI: 10.3171/2015.5.JNS15145. 

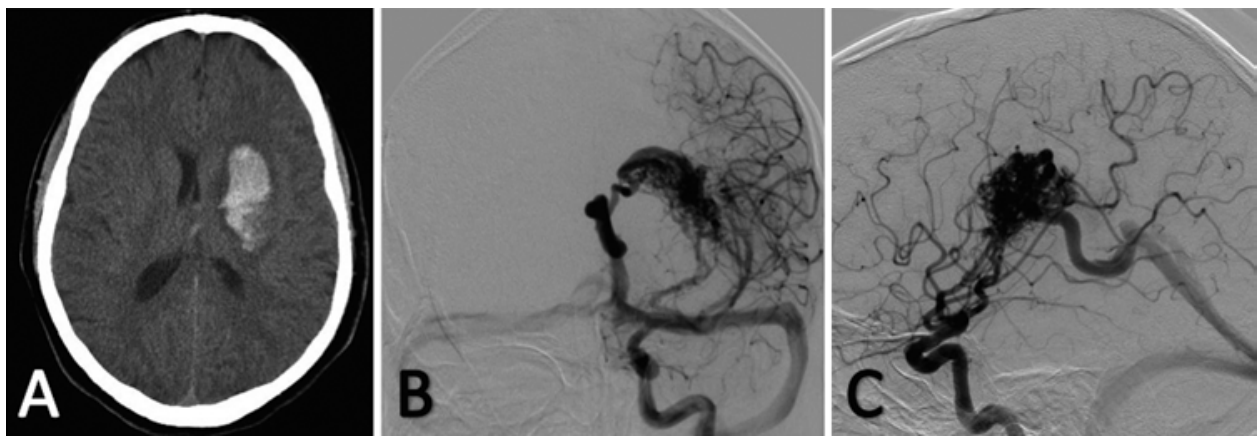

FIG. 1. Unenhanced brain CT scan showing a 4-cm-deep hematoma on the left side (A). Brain DSA in anteroposterior view, arterial phase, showing a claustral bAVM mainly fed by left lenticulostriate arteries (from the lateral and medial groups) and deep perforating branches from the $\mathrm{M}_{2}-\mathrm{M}_{3}$ segment of the left middle cerebral artery. Its nidus measures $35 \mathrm{~mm}$ (B). Brain DSA in lateral view, arterial phase, showing a unique deep venous drainage through the left internal cerebral vein into the straight sinus via the vein of Galen (C).

arteries (from the lateral and medial groups) and deep perforating branches arising from the $\mathrm{M}_{2}-\mathrm{M}_{3}$ segment of the left middle cerebral artery. The nidus was compact and measured $35 \mathrm{~mm}$. There was a unique deep venous drainage through the left internal cerebral vein (Fig. 1B and C). The bAVM was thus classified as Spetzler-Martin Grade IV. ${ }^{12}$

After the case was discussed during a multidisciplinary round, the treatment strategy chosen was to partially embolize the nidus to decrease its size and subsequently treat the remnant by Gamma Knife radiosurgery. An initial embolization session was performed 5 weeks after the onset of symptoms, upon complete resorption of the hematoma. Under general anesthesia, a 6-Fr Envoy (Cordis) was placed in the left internal carotid artery via a 6-Fr femoral sheath. Then, a 1.2 Magic microcatheter (Balt) was navigated under continuous subtracted fluoroscopy (Artis biplane angiosuite; Siemens), and $0.7 \mathrm{ml}$ of NBCAbased acrylic glue (Glubran; GEM Italy) at 20\% dilution was injected in a lenticulostriate artery that was feeding the AVM. The control run after injection showed a partial nidus occlusion with no venous migration of the embolic agent.

Subsequently, another 1.2 Magic microcatheter was placed in a deep perforating branch from the $\mathrm{M}_{2}$ segment of the left middle cerebral artery (Fig. 2A). Under fluoroscopic guidance, $0.7 \mathrm{ml}$ of NBCA (20\% dilution) was injected. A control angiographic run after injection showed no apparent complication (Fig. 2B). Another control run was then performed, using front and lateral views, which revealed an NBCA migration in the straight sinus, with a flow reduction (Fig. 2C and D). Anticoagulation treatment was immediately started via a 4000 IU bolus of heparin. A decision was made to recover the glue cast using a stent retriever via a venous route.

A left internal jugular vein access via a 6-Fr sheath was used. A Fargo 6-Fr supple guiding catheter (Balt) was navigated through the left lateral sinus over a Rebar 27 microcatheter (ev3/Covidien). A Solitaire FR $4 \times 20$ $\mathrm{mm}$ stent (ev3/Covidien) was inserted for 1 minute in the straight sinus via the microcatheter and subsequently retrieved (Fig. 3A).

Most of the glue cast was captured by the meshes of the Solitaire device after 2 passages (Fig. 3B). The con- trol angiographic run showed a subtotal flow restoration within the straight sinus, without contrast stagnation in the venous phase (Fig. 3C and D). The result was judged satisfactory and the procedure was then stopped.

Control brain CT after the procedure showed no hemorrhagic complications. The patient awoke in an unchanged neurological status. Anticoagulation treatment was continued for 4 days and the patient was discharged on Day 10, with no worsening of his preexisting hematoma-related neurological deficit. A second embolization was scheduled to further reduce the size of the AVM before radiosurgery. The second session was performed without complications, and 50\% devascularization of the
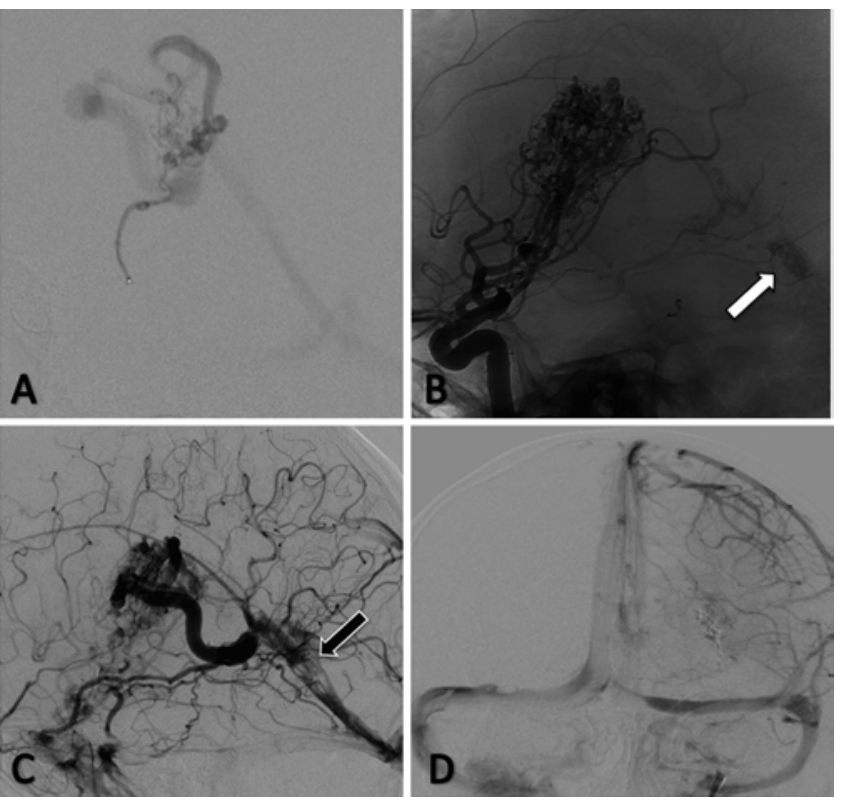

FIG. 2. Brain DSA in right oblique view, arterial phase, showing superselective catheterization in a feeding lenticulostriate artery, before NBCA injection (A). An unsubtracted lateral view showing the presence of radiopaque glue (white arrow) within the venous drainage, distal to the AVM nidus (B). Brain DSA in lateral view, arterial phase, after NBCA injection, showing a glue leak in the straight sinus (black arrow) (C). Brain DSA in anteroposterior view, late venous phase, showing contrast stagnation in the left lateral sinus (D). 

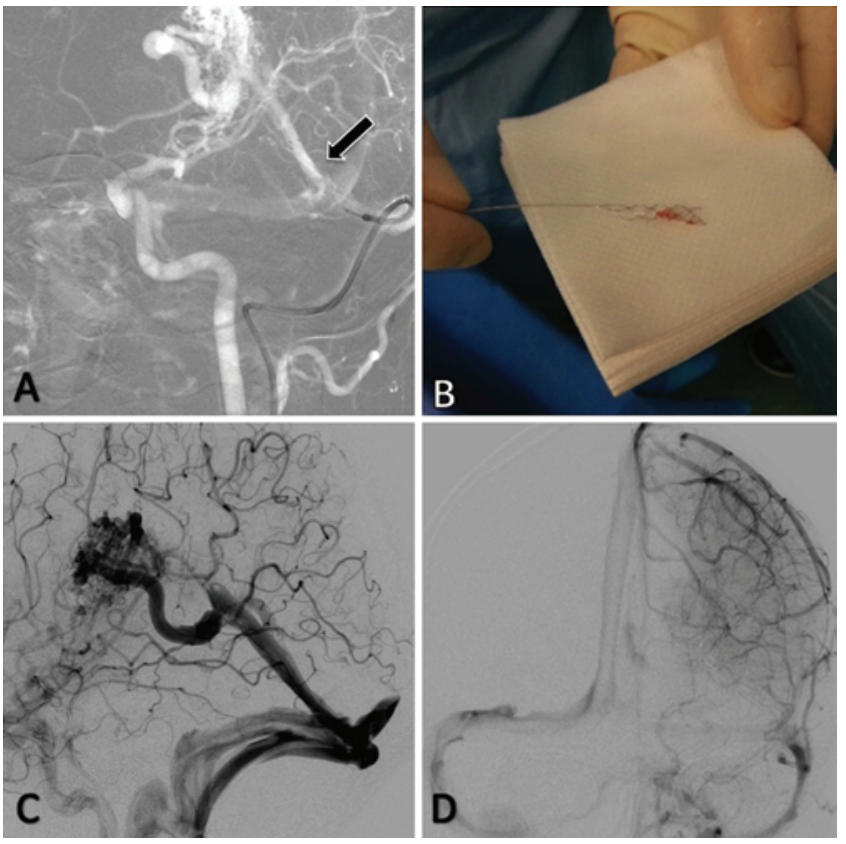

FIG. 3. Brain DSA, in left oblique view, showing a roadmap through the left internal carotid artery and catheterization of the left lateral sinus with Fargo 6-Fr and Rebar 27. A Solitaire stent was inserted in the straight sinus (black arrow) (A). A picture of the Solitaire stent after retrieval, showing NBCA fragments captured in the device (B). Brain DSA in lateral view, arterial phase, after NBCA removal, showing a major reduction of the glue cast within the straight sinus (C). Brain DSA in anteroposterior view, late venous phase, showing that there is no more contrast stagnation visible in the left lateral sinus (D). Figure is available in color online only.

lesion was achieved. The patient subsequently underwent Gamma Knife radiosurgery to complete treatment of the AVM.

\section{Discussion}

Although treatment for unruptured bAVMs remains controversial, ${ }^{8}$ a consensus exists concerning the need for complete obliteration of ruptured AVMs, given the nonnegligible risk of rehemorrhage. ${ }^{1}$ The treatment strategy varies according to the experience and equipment of different institutions, but a multidisciplinary approach is generally adopted. Stand-alone Gamma Knife radiosurgery is generally accepted for the treatment of such deep-seated lesions, with a hemorrhagic risk ranging from $1 \%$ to $2 \%$ in the first 3 years after treatment for unruptured AVMs. ${ }^{5}$

In the case presented here, however, because we had good arterial access to the AVM, we chose to perform a preliminary endovascular embolization to decrease the lesion volume and flow within the nidus. By doing this, we hoped to accelerate the healing process and allow a reduction of the radiation dose during radiosurgery. Also, because liquid embolic agents present the advantage of immediately stopping the blood flow within the treated shunt, such an approach may therefore increase the probability of rapidly excluding the bleeding point before subjecting the patient to radiosurgery. The use of Onyx (ev3/Covidien) was excluded in this case due to the risk of an excessive penetration of the embolic agent into small perinidal vessels vascularizing the normal tissue in a highly eloquent area of the brain. Moreover, the microcatheter for NBCA injection shows, in our experience, better navigability within small, tortuous feeders. Of all therapeutic options, surgery was excluded in this case due to the size and deep location of the AVM in eloquent areas of the brain, accounting for a relatively high Spetzler-Martin grade.

Complications linked to embolization are mostly hemorrhagic in nature ${ }^{7}$ and may be due to perforation of the feeder or delayed bleeding secondary to venous drainage impairment. Still, embolic agent migration is a dreaded complication during an AVM embolization. Therefore, control DSA after Onyx or glue injection should always be performed under several projections. In our case, the venous migration was more visible in the lateral view, which was not the view used during the injection. The choice of using a high dilution ratio (NBCA [20\%] diluted with ethiodized oil [80\%]) may have increased the risk of venous migration, but was justified by the fact that we wanted to maximize the penetration of the embolic agent into a relatively compact plexiform nidus.

There are cases of Solitaire use in cerebral venous thrombosis. ${ }^{910}$ To our knowledge, this is the first case reported in the literature of a Solitaire FR device used for rescue following an involuntary acrylic glue migration into the draining vein. A stent-retriever device has already been used to retrieve coils, both in arterial and venous circulation. ${ }^{4,6}$ Physicians should always be particularly careful when using such devices in the venous circulation, because veins are known to have more fragile walls than arteries. However, safe use of the Solitaire device in cases of venous sinus thrombosis has already been reported, even in very delicate settings (such as in children). ${ }^{11}$

\section{Conclusions}

The case presented here shows the feasibility of glue cast retrieval from within a dural sinus using the Solitaire FR device. Stent retrievers may be valuable devices for rescue removal of embolic agents, such as NBCA, in cases of uncontrolled glue migration into the venous system. This could avoid postoperative intracranial bleeding due to venous drainage compromise.

\section{References}

1. Fleetwood IG, Steinberg GK: Arteriovenous malformations. Lancet 359:863-873, 2002

2. Graf CJ, Perret GE, Torner JC: Bleeding from cerebral arteriovenous malformations as part of their natural history. $\mathbf{J}$ Neurosurg 58:331-337, 1983

3. Hofmeister C, Stapf C, Hartmann A, Sciacca RR, Mansmann U, terBrugge K, et al: Demographic, morphological, and clinical characteristics of 1289 patients with brain arteriovenous malformation. Stroke 31:1307-1310, 2000

4. Kabbani MR, Smith A, Leider M: Endovascular coil retrieval using a TrevoProVue stentriever. J Neurointerv Surg 7:e19, 2015

5. Latorzeff I, Schlienger M, Sabatier J, Borius PY, Bourdin $\mathrm{S}$, Menegalli D, et al: [Radiosurgery for brain arteriovenous malformations.] Cancer Radiother 16 Suppl:S46-S56, $2012(\mathrm{Fr})$

6. Liu KC, Ding D, Starke RM, Geraghty SR, Jensen ME: In- 
traprocedural retrieval of migrated coils during endovascular aneurysm treatment with the Trevo Stentriever device. J Clin Neurosci 21:503-506, 2014

7. Lundqvist C, Wikholm G, Svendsen P: Embolization of cerebral arteriovenous malformations: Part II--Aspects of complications and late outcome. Neurosurgery 39:460-469, 1996

8. Mohr JP, Parides MK, Stapf C, Moquete E, Moy CS, Overbey JR, et al: Medical management with or without interventional therapy for unruptured brain arteriovenous malformations (ARUBA): a multicentre, non-blinded, randomised trial. Lancet 383:614-621, 2014

9. Pukenas BA, Kumar M, Stiefel M, Smith M, Hurst R: Solitaire FR device for treatment of dural sinus thrombosis. J Neurointerv Surg 6:e2, 2014

10. Raychev R, Tateshima S, Rastogi S, Balgude A, Yafeh B, Saver JL, et al: Successful treatment of extensive cerebral venous sinus thrombosis using a combined approach with Penumbra aspiration system and Solitaire FR retrieval device. J Neurointerv Surg 6:e32, 2014

11. Shaikh H, Pukenas BA, McIntosh A, Licht D, Hurst RW: Combined use of Solitaire FR and Penumbra devices for endovascular treatment of cerebral venous sinus thrombosis in a child. J Neurointerv Surg 7:e10, 2015

12. Spetzler RF, Martin NA: A proposed grading system for arteriovenous malformations. 1986. J Neurosurg 108:186-193, 2008
13. Stapf C, Labovitz DL, Sciacca RR, Mast H, Mohr JP, Sacco $\mathrm{RL}$ : Incidence of adult brain arteriovenous malformation hemorrhage in a prospective population-based stroke survey. Cerebrovasc Dis 13:43-46, 2002

\section{Disclosures}

Dr. Sourour is a consultant for Covidien.

\section{Author Contributions}

Conception and design: Di Maria, Fahed, Clarençon. Acquisition of data: Fahed, Clarençon. Analysis and interpretation of data: Di Maria, Fahed, Clarençon. Drafting the article: Di Maria, Fahed, Clarençon. Critically revising the article: all authors. Reviewed submitted version of manuscript: all authors. Approved the final version of the manuscript on behalf of all authors: Di Maria. Administrative/technical/material support: Di Maria, Fahed. Study supervision: Di Maria.

\section{Correspondence}

Federico Di Maria, Department of Interventional Neuroradiology, Pitié-Salpêtrière Hospital, Paris VI University, 47-83 Boulevard de 1'Hôpital, Paris 75651, France. email: federico.dimaria@ gmail.com. 